\title{
CONDILLAC E O ENSINO DE CIÊNCIAS: QUE RELAÇÕES PODEMOS ENCONTRAR AINDA HOJE? ${ }^{1}$
}

\section{Condillac and science teaching: what relationships can we still find today?}

\author{
Maria Emília Caixeta \\ FAE-UFMG - Email: mecdcl@uol.com.br
}

\begin{abstract}
...em um mesmo espaço de tempo, uns vivem muito mais que os outros, pois viver é gozar, e a vida é mais larga para aquele que sabe multiplicar mais os objetos de seus gozo.

(Condillac, Tratado das Sensações)
\end{abstract}

\section{Resumo:}

Via de regra, pouco nos ocupamos em pensar as epistemologias que sustentam e orientam as ações em sala de aula. Há um relativo consenso de que os livros didáticos desempenham um papel importante na definição dos currículos ${ }^{2}$. O objetivo deste trabalho será, pois realizar uma leitura da sala de aula de ciências da primeira série do Ensino Fundamental quanto às suas filiações epistemológicas. Para isso, será analisado um conjunto de atividades de ensino extraído de uma coleção de ciências destinada ao nível fundamental. Esse estudo será complementado ainda com entrevistas realizadas com estudantes desse nível de ensino. A discussão dessas lições de aula está referenciada na corrente sensualista e na história dos manuais didáticos de ciências. Os princípios filosóficos iluministas foram tomados com vista a auxiliar na interpretação da origem de algumas idéias recorrentes no ensino de ciências, por exemplo, no que diz respeito à importância que os órgãos dos sentidos desempenha na compreensão e explicação do mundo natural. $\mathrm{Na}$ confluência do racionalismo cartesiano e iluminista emergiu uma orientação teóricometodológica de cunho empírico-sensualista que perdura até hoje nas práticas escolares, sem que se proceda a uma análise crítica dessa orientação fundamentada na epistemologia contemporânea.

Palavras-chave: livros didáticos de ciências, ensino fundamental de ciências

\section{Abstract:}

Usually, we don't thinking about the epistemologies that support and guide the actions in classrooms. There is a relative consensus that the textbooks play an important role in the definition of science curricula. The aim of this article is to analyze the epistemological filiations in the science textbooks for elementary school. Activities from a series of science textbooks for elementary-middle school were analyzed, considering a review of the history of didactic manuals. The study was complemented with interviews with

\footnotetext{
${ }^{1}$ Este estudo foi apresentado como trabalho final do Curso Psicologia e Linguagem, ministrado pelas professoras Regina Souza e Lucy Banks na Unicamp, no segundo semestre de 1998.

${ }^{2} \mathrm{O}$ termo currículo aqui está sendo entendido no seu sentido amplo, para designar o conjunto de orientações das práticas pedagógicas que se materializa através dos conteúdos específicos, das estratégias e procedimentos adotados, dos recursos instrucionais mobilizados, dos objetivos e metas definitos.
} 
students of this level of education. The illuminists' philosophical principles had been taken to assist in the interpretation of the origin of some recurrent ideas in the education of sciences, for example, in respect to the importance that the senses have in understanding and explaining the natural world. In the confluence of the Cartesian and illuminist rationalism emerged a theoretical-methodological orientation with an empiricist-sensualist nature that persists until today in school practices without a critical analysis of this orientation based on the contemporary epistemology.

Key-words: science textbooks, elementary school science teaching 


\section{OS SENSUALISTAS DO SÉCULO XVIII: UM BREVE HISTÓRICO}

Ao contrário, embora também racionalistas, os iluministas não consideravam o conhecimento científico privilégio de poucos. O lluminismo do século XVIII pode ser caracterizado pela sua forte vocação pela educação tida como a base do intelecto. Locke (1632-1704) e Condillac (1714-1780) elaboraram uma teoria sensualista do conhecimento a partir da premissa de que a base da vida mental é as sensações. Eles se destacaram como nomes expressivos da corrente sensualista na crítica ao inatismo ${ }^{3}$ do século anterior. Para os inatistas as idéias seriam inerentes ao próprio intelecto humano e através do método cartesiano acreditava-se progredir na busca da verdade e poder chegar ao conhecimento da realidade.

Do ideal de igualdade iluminista, já que ninguém nasce inteligente nem muito menos com inteligência maior ou menor que a dos outros, derivou a proposição de que qualquer homem poderia vir a ser chefe ou dirigente, numa nítida relação entre conhecimento e poder. A educação foi defendida como um direito de todos, posto que qualquer sujeito fosse ele louco, doente ou deficiente poderia vir a conhecer o mundo, desde que educado.

Condillac foi profundamente influenciado por Locke, apesar de considerá-lo bastante genérico. Segundo Locke, a mente é como um papel em branco desprovido de todos os caracteres, sem nenhuma idéia prévia. De onde então viria a razão e o conhecimento? Da experiência, seria a resposta. As experiências com os objetos sensíveis levam para a mente as diferentes percepções das coisas. O cérebro seria inicialmente vazio, mas plástico, pois é capaz de ser marcado pelas experiências externas como se marca uma figura em alto relevo numa cera mole ou um texto em disquete virgem. Em outras palavras, o aperfeiçoamento humano resultaria da impressão da realidade no intelecto pela sensação que fosse capaz de nos causar.

Para Condillac (1984/1754) o conhecimento, também, resulta da experiência com o mundo. A superioridade moral observada na espécie humana devia-se apenas a uma condição de civilização dada pela sensibilidade ao mundo. A sensibilidade por seu turno resulta da capacidade imitativa dos homens. Quanto maior fosse a possibilidade de vivenciar experiências de imitação maior seria a ampliação do campo das sensações bem como a procura de outras novas sensações e necessidades.

O desenvolvimento do espírito humano dar-se-ia pela educação dos órgãos dos sentidos através do registro das impressões resultantes do contato do sujeito cognoscente com o mundo exterior.

Através do seu Tratado sobre as sensações, essas idéias de Condillac desempenharam ampla influência nos ideais iluministas durante todo o século XVIII o que Ihe valeu a direção da educação do príncipe de Parma. Posteriormente Condillac publicou dezesseis volumes sobre o curso que fornecera ao príncipe (Os Pensadores, 1984/1754). Nos Ensaios sobre a origem dos conhecimentos humanos afirmou que a sensação é a única fonte de nossos pensamentos, princípio pelo qual se pautou ao esboçar uma teoria da linguagem.

\footnotetext{
${ }^{3} \mathrm{O}$ inatismo se caracteriza pela crença de que o entendimento comporta certos princípios originários, isto é, certas noções primárias ou, que estariam estampados na mente humana, cuja alma as recebera desde que nascemos. Tão logo os homens começam a usar a razão os princípios inatos tornam-se conhecidos. A posse do uso da razão, segundo os inatistas, dar-se-ia pelo estudo metódico e organizado dedutivamente por Descates.
} 
O Tratado das Sensações apresenta um detalhamento meticuloso a partir da proposição de estudar cada sentido separadamente, numa tentativa de superação da crítica a Locke de que sua doutrina teria sido demasiadamente genérica, isto é, distinguindo cada idéia originada a partir do sentido treinado.

A metáfora da estátua de mármore é utilizada por Condillac (1984/1754) para explicar como seria o interior de um homem, animado por uma alma que desconhece o mundo. Assim, despertando os sentidos um a um, de maneira que estes pudessem se influenciar mutuamente, as operações do entendimento seriam despertas.

O pressuposto básico era de que ao recebermos todos os estímulos simultaneamente isso causaria um embaralhamento das idéias. Da percepção das coisas do mundo geraria a consciência dessas coisas, isto é, o desembaralhamento das sensações. Para se chegar à percepção e à consciência era necessário seguir rigorosamente as lições indicadas e apresentadas separadamente.

\section{O CONHECIMENTO VEM DOS SENTIDOS OU O DESPERTAR DOS SENTIDOS DE VICTOR}

O caso do menino Victor de Aveyron é exemplar de como os sensualistas aplicaram suas idéias na educação. Victor foi uma criança encontrada por caçadores quando tentava fugir subindo em uma árvore de um bosque nos arredores de Paris. Possuía aproximadamente quatorze anos e aparentava não ter nenhuma experiência com a civilização. Pego pelos caçadores, chegou à Paris em 1800 onde serviu de objeto de curiosidade das pessoas até que fora levado para Paris ficando aos cuidados do médico Jean Itard.

Itard, no relatório de 1801, feito a Sua Excelência o Ministro do Interior, discute as ações tentadas com o menino para torná-lo sensível e ensiná-lo a linguagem, bem como analisa detidamente cada uma dessas ações e seus efeitos na constituição de um novo indivíduo falante e com idéias desembaralhadas, propósito este fracassado. Tal como na estátua de mármore de Condillac, Itard (1801) espera animar a alma do menino selvagem marcada por um comportamento, segundo ele até mesmo inferior ao dos animais domésticos - para conhecer o mundo. Atitude semelhante podemos encontrar, ainda hoje, nas iniciativas em sala de aula de ciências que discutiremos mais adiante.

As bases das lições de Itard (1801) com o menino selvagem, foram tomadas de Condillac (1984/1754). O olfato seria o ponto de partida, pois se trata do sentido mais pobre de todos. Visão, audição e fala, seriam complicados e ficariam para o fim. Itard (1801) faz esse percurso com o menino selvagem a partir de cinco metas pré-estabelecidas. A Primeira meta é a ambientação, respeitando as vontades do menino, andava nu, comia quando quisesse e dormia pelos cantos. A segunda meta se caracteriza pela tentativa de desenvolver o espírito e a atenção através de estímulos enérgicos e com as mais vivas afeições da alma. Com a terceira meta pretendia-se alargar no menino a esfera das idéias. A brincadeira de encontrar objetos escondidos foi amplamente explorada visando exercitar a atenção e a memória. Na quarta meta, para o médico, o mais importante de ser alcançado estava relacionado com a capacidade de falar, isto é, levá-lo ao uso da palavra, através da imitação pela necessidade criada, por exemplo, de pedir leite, bebida apreciada por Victor. A quinta meta o objetivo era de exercer sobre os objetos de sua experiência imediata, as 
operações mais simples e posteriormente, determinando-lhe a aplicação aos objetos de ensino, isto é, com coisas que não tivessem relação com as necessidades imediatas.

A relação entre pensamento e linguagem é importante de ser explicitada neste contexto para entendermos o porquê da necessidade de se fazer com que Victor falasse. Para Condillac (1984/1754), as idéias, a princípio estão todas muito misturadas. Elas aparecem simultaneamente amalgamadas e, portanto confusas necessitando serem desmisturadas. Já a fala teria como característica a linearidade e a seqüenciação tendo, portanto a função de organizar o pensamento. Desta maneira é possível dizer que haveria assim uma forte relação entre pensamento e palavra.

Assim, Victor de Aveyron precisava falar. A fala no menino selvagem seria alcançada através do exercício dos órgãos articulatórios. A fixação de Itard (1801) em fazer com que o menino falasse residia, pois, nos pressupostos teóricos epistemológicos tomados de Condillac (1984/1754) de que ao falar ele daria provas da desconfusão do seu espírito e de que, de fato, teria conhecido o mundo.

\section{PROCEDIMENTOS PARA ANÁLISE}

Alguns procedimentos metodológicos foram adotados no desenvolvimento desse estudo. Foram selecionados inicialmente dois manuais didáticos : Oliveira e Wykrota, $1990^{4}$ e Blinder e col. 1996, dois manuais que se aproximarem no que diz respeito às suas filiações epistemológicas. Esse fato dispensa o estudo em separado de cada um deles. Selecionamos para análise apenas uma unidade de ensino, proposta por Oliveira e Wykrota, por enfocar os sentidos de maneira mais explícita, extensa, detalhada e próxima de outros manuais que fizeram a história do ensino de ciências.

A análise está sustentada na confluência de três casos: o do menino selvagem que ficou conhecido como Victor de Aveyron, o da metáfora da estátua de mármore de Condillac e o caso de dois estudantes do ensino fundamental submetidos aos exercícios dos sentidos apresentados pelo livro didático analisado. Alguns episódios sobre as iniciativas de Itard (1801) com o menino selvagem serão utilizados aqui, ainda que de forma pouco aprofundada, na tentativa de compreender o que há de comum com as pedagogias atuais na educação em ciências.

A história dos manuais didáticos auxilia na compreensão do modo como essas idéias perduram anos a fio sem que se proceda à crítica das epistemologias que sustentam as escolhas dos autores e, conseqüentemente, de nós professores. É possível estabelecer algumas aproximações entre as lições propostas nesses manuais didáticos destinados à educação infantil com o protocolo desenvolvido com o menino Victor, a partir de 1801 e as crianças Mateus e Daniel, estudantes na atualidade.

Blinder e col. (1996) iniciam o livro com o estudo da criança em três capítulos intitulados: Em contato com o mundo, Você sabe o que estou sentindo? e Meu corpo. Os objetivos explicitados dizem que no capítulo um o estudo tem por objetivo sensibilizar a criança na percepção de que seu corpo é um veículo de contato com o mundo circundante; no segundo capítulo o objetivo é que a criança tome ciência dos cinco órgãos dos sentidos e

\footnotetext{
${ }^{4}$ Uma versão mais atualizada dessa coleção foi publicada em 2000. Contudo, continua sendo pertinente o estudo relatado nesse artigo, pois as atividades são as mesmas na sua essência.
} 
no terceiro capítulo explicita a idéia de que é por meio das diferentes imagens que a criança deverá ser capaz de perceber as formas de exteriorização de emoções e sensações.

De modo semelhante, a unidade didática intitulada Viver é Sentir é o primeiro contato da criança proposta por Oliveira e Wykrota (1990) na primeira série. Ela é dedicada ao estudo das sensações através da exploração de órgãos dos sentidos pelo olfato, seguido do tato. Na seqüência aparecem os estudos da visão, novamente o olfato e, por último, audição e fala. Esse estudo, tal como o fez Itard (1801) vem proposto em forma de lições.

\section{LIÇÃO NÚMERO 1: Crescendo e aprendendo}

Trata-se de uma proposta de autoconhecimento onde a criança se olha no espelho, se apalpa de corpo inteiro, repara as diferenças entre meninos e meninas e resgata sua própria história de vida. No Livro do Professor as autoras afirmam que a intenção com essa unidade de ensino é, entre outras coisas, de

colocar a criança em contato com sua identidade corporal e psico-social. Incentivar a criança a observar seu próprio corpo e o dos colegas, estimulando-a a formular hipóteses e explicações para as semelhanças e diferenças entre pessoas, para o jeito de cada um ser e para que a criança perceba que cada um de nós é uma pessoa única, inteira, capaz de sentir, pensar e agir (Oliveira e Wykrota, 1990, p.26).

A questão da identidade se insere na teoria sensualista pela capacidade de nos apercebermos ao longo das modificações que vamos sofrendo. $\mathrm{O}$ que se entende por eu, não remete a um presente que é continuidade de um passado, ou seja, a consciência do eu vem na medida em que somos capazes de perceber nas mudanças o mesmo que temos sido. O eu é, assim, o que resulta das sensações experimentadas e que a memória recorda do que temos seguido sendo. "Esta observação confirma que, em primeiro instante de sua existência, a estátua não pode sentir desejos, pois antes de dizer eu desejo é preciso haver dito eu" (Mondolfo, 1947/1963, p.105). A passagem do mundo interior ao exterior, isto é do mundo subjetivo ao objetivo não pode, segundo Condillac (1984/1754) acontecer senão por meio do tato que é o sentido da realidade. No início do processo de desenvolvimento, a criança, assim como a estátua de Condillac, não pode sentir, nem pode conhecer outra coisa senão a si mesma e sua maneiras de ser.

A faculdade de sentir seria a primeira das faculdades da alma. A alma sente pela visão, pela audição, pelo olfato, pelo paladar e principalmente pelo tato. Entretanto, o fato de vermos e ouvirmos não são, para o autor, garantia de conhecimento dos objetos. Em outras palavras, não basta possuir os sentidos, pois mesmo aqueles que os possui não gozam do mesmo conhecimento. A posse do conhecimento resulta das diferentes maneiras pelas quais utilizamos os sentidos. "Os sentidos são apenas a causa ocasional das impressões que os objetos exercem sobre nós. É a alma que sente; somente a ela as impressões pertencem; e sentir é a primeira faculdade que notamos nela" (Condillac, 1780/1984, p.65).

\section{Sensações... descobertas...}

O cheiro da pipoca é explorado através da leitura de imagens. Ao final é sugerido que a criança, supostamente ainda não alfabetizada, junto com a turma e a professora, conte uma história sobre as sensações e descobertas do menino a partir da ilustração do livro. 
A imagem da estátua de mármore é evocada por Condillac para comparar com o homem. Carente da faculdade de pensar e sem comunicação com o mundo externo. Seria organizada interiormente como nós, mas cujo exterior de mármore, não permitiria que nenhum dos sentidos fosse usado. Os conhecimentos da estátua - privada de qualquer idéia - só podem ser atingidos pelos odores que chegam até ela. "Não pode ter idéia de extensão, figura nem de nada que esteja fora dela ou fora de suas sensações, nem tão pouco as idéias de cor, de som ou de sabor" (1947/ 1963, p.67).

Os odores para Condillac são a chave para a atenção. "Ao primeiro odor, a capacidade de sentir de nossa estátua se concentra por inteiro na impressão que recebe seu órgão. Isto é o que eu chamo atenção" (Mondolo, 1947/1963, p.69)

A atenção faz com que as sensações possam ser desembaralhadas, pois ela vem do fato de poder distinguir cada uma das sensações. Nesse sentido a motivação é externa, vem da captura dos sentidos. O que motiva o menino com a pipoca é o cheiro que ela exala. Em outras palavras, a idéia de Condillac (1984/1754) é de que as operações do entendimento -atenção, percepção, consciência, memória, imaginação, reflexão e análise seriam constituídas pelos estímulos do indivíduo e pelo processo de educação. A educação consistiria, então, no aguçamento de cada sentido em separado.

O cheiro da pipoca e a memória que tal odor provoca participam na capacidade de sentir prazer, necessidade, desejo, saudade, etc. O pressuposto sensualista é de que o cheiro da pipoca conectaria o passado com a sensação presente. A experiência de já ter sentido o cheiro da pipoca, associado ao prazer de comê-las subsistiria no cérebro.

Ao passar, deste modo, por duas maneiras de ser, a estátua sente que já não é o que tem sido: o conhecimento dessa mudança lhe faz relacionar a primeira maneira de ser com um momento diferente em que experimenta a segunda: e isto é o que a move a distinguir entre existir de uma maneira e dar-se conta de haver existido de outra (Mondolo, 1963, p.72).

\section{LIÇÃO NÚMERO 2: Com...tato}

A proposta do livro quanto à exploração dos órgãos dos sentidos é de iniciar pelo tato, para Condillac (1984/1754) o mais importante e simples de todos eles, pois é o tato que ensina os outros sentidos a julgar os objetos externos.

A atividade é ilustrada por uma criança tomando banho de chuveiro e vem interrogando a criança sobre o que acontece com o nosso corpo quando nadamos, tomamos sol, brincamos com água e terra. Informa sobre a importância da pele na proteção do corpo e no contato com o meio, a atividade se encerra com um convite a observarem a sensações do corpo ao contato com a água, o sol e a lama.

\section{Enxergando com as mãos}

O estudo do tato continua com as autoras informando que a criança irá trabalhar com três caixinhas. Cada uma delas contendo coisas diferentes. Sem olhar devem tocar nas coisas que estão no interior delas. A sugestão é de que troque idéias com os colegas sobre o que ela sentiu ao fazer a experiência Outras atividades estão propostas, como tocar um colega com uma pena, andar descalço no cascalho e na grama. As lições sobre higiene corporal e cuidados com o corpo fazem parte do estudo de cada sensação. Quatro situações seqüenciais são apresentadas: na primeira uma criança está brincando, na segunda a criança fura o pé com um prego, na terceira lava o machucado com água e 
sabão e na última está com um curativo no pé. Em seguida duas situações são exploradas sobre exposição adequada e inadequada de nossa pele ao sol. A pergunta final é o que ou sobre o que elas descobriram sobre o sentido do tato.

Daniel (8 anos), entrevistado sobre as aulas de ciências correspondentes a essas lições, relata como a professora procedia quando do estudo do tato:

...ela pegava uma caixa com um furo e a gente enfiava a mão lá dentro, ai a gente tinha que acertar encostando a mão lá dentro, assim...(repete o gesto de que procura algo dentro de uma caixa), eu acertei tudo, tinha um pneu, uma bolsa de dor de cabeça (bolsa térmica), uma corda... O outro eu não sei não.

Mateus (13 anos) ao ouvir Daniel relatar sua experiência sensualista se sente também animado e comenta sua aula de ciências quando fez a primeira série:

comigo aconteceu assim: eles utilizaram uma sala vazia e colocaram lá dentro um monte de caixas rasas de madeira, cada uma delas continha uma coisa diferente, areia, pedras, milho, geleca, lixa e umas outras coisas. Sobre uma mesa tinham outras caixas com objetos para serem tocados com as mãos, enquanto que as primeiras, espalhadas pelo chão eram tocadas com os pés.

Com os olhos vendados e guiados pela professora cada criança era submetida à experiência de tocar em objetos e materiais de diferentes texturas. Depois de submetidos ao exercício retiravam-se as vendas dos olhos e assim podiam ver do que se tratava cada objeto que lhe causara cada uma das diferentes sensações.

O menino selvagem teve o tato estimulado em variadas situações. Victor inicialmente tirava batatas quentes diretamente do fogo com as mãos, decorrido algum tempo de convivência familiar desenvolve a sensibilidade ao tato sendo capaz de experimentar a textura das batatas cozidas com as pontas dos dedos e de devolvê-las ao fogo quando não estavam, ainda, devidamente amolecidas. A tentativa de exposição de Victor, pela segunda vez, a choques provenientes de uma garrafa de Leyde, ligeiramente carregada, foi infrutífera. Itard (1801) num momento que estendeu o seu braço para agarrar Victor tomou o choque provocado pelo menino. Mas no seu relatório considera que com o selvagem o resultado melhor que obteve com o tato foi dando-lhe banhos quentes. Em pouco tempo Victor já mergulhava a mão da criada da casa na banheira num gesto indicativo de que a água não estava do seu agrado.

\section{LIÇÃO NÚMERO 3: Olho Vivo!}

A atividade fala da relação entre luz e visão, além de fazer um breve estudo da anatomia do olho e função dos cílios, pálpebras, lágrimas e cuidados a serem tomados com os olhos. O arco-íris é o contexto apresentado para o estudo das cores.

\section{Os olhos e os sentimentos}

Para as autoras os olhos podem ser entendidos, como para Chaui (1988), como janelas da alma, espelho do mundo. Dizem elas:

Os olhos são como duas janelas. Que acontece quando abrimos as janelas de uma casa? Quem está dentro vê o que está lá fora. E quem passa em frente à janela aberta? Vê também um pouquinho do que existe dentro da 
casa. O jeito de olhar é muito importante para você mostrar e perceber sentimentos (Wikrota, 1990, p 18).

As crianças dessa atividade devem associar os sentimentos expressos no desenho de três carinhas: uma triste, outra brava e a terceira feliz. Victor e as crianças precisavam aprender o mundo pelo o olhar. Os olhos de Victor são descritos como incapazes de se conservarem fixos, sem expressão, passando vagamente de um objeto para outro sem nunca se deterem em nenhum. Eram, no julgamento de Itard (1801), tão pouco educados e exercitados pelo tato, que não podiam distinguir um relevo de uma pintura (1801, p.138).

\section{LIÇÃO NÚMERO 4: Cheiros no ar}

Além da observação do nariz e discussão de ar e micróbios a atividade relaciona olfato com as reminiscências, através do texto a seguir:

História com Cheiros

Chico dos Bonecos.

Cheiro de alho na cozinha.

Cheiro de sabão no quintal.

Cheiro de pipoca na calçada.

Tudo isso tem cheiro de Sábado...

Cheiro de peixe na cozinha.

Cheiro de cimento molhado no quintal.

Cheiro de algodão doce na calçada.

Tudo isso tem cheiro de Domingo...

Cheiro de leite na cozinha.

Cheiro de banana madura no quintal.

Cheiro de fumaça na calçada.

Tudo isso tem cheiro de Segunda-feira (Oliveira e Wykrota, 1990: p.22).

Nessa atividade a criança é solicitada a indicar como ela associa os cheiros aos dias da semana dela. A expressão de que algo não está cheirando bem, é muito usada para dizer que alguma coisa está errada ou não vai bem, possivelmente trata-se de uma herança sensualista.

\section{A brincadeira de farejar}

A proposta é sair pela escola percebendo cheiros (sala de aula, jardim, cantina, banheiro, pátio...), prestando bastante atenção. Anotar os cheiros que lhe agradam e os que não agradam e depois relatar o que descobriu percebendo cheiros pela escola. Três experiências diferentes podem ser sintetizadas na atividade que envolve o olfato. $A$ do menino Victor e a das crianças nos dias atuais na sala de aula de ciências. É possível estabelecer algum grau de aproximação? Eu diria que sim, guardadas as devidas proporções. 
Itard (1801) com a sua segunda meta pretendia despertar a sensibilidade nervosa do menino selvagem com os estímulos mais enérgicos, por exemplo, através da introdução de tabaco no nariz de Victor, dos banhos quentes e das friç̧ões no corpo, dado que a princípio ele "aceitava com a mesma indiferença o odor dos perfumes e a exalação fétida do lixo que Ihe recobria a cama..." (p.138).

Daniel (8 anos), ao relatar a atividade que a professora desenvolvera em sala de aula com as crianças diz que: "a gente ia lá na frente, aí ela tampava nossos olhos e dava uma coisa para a gente cheirar e a gente tinha que acertar". Perguntado sobre que coisas eram essas Daniel relata: "shoyu, álcool, pimenta, perfume e só. Eu fiz, fiz o álcool e acertei".

Para Condillac (1947/1963) o único meio de adquirir conhecimento é o que a natureza nos ofereceu, isto é, observando e colocando nossos juízos a prova da observação e da experiência. Nos dizeres do autor, interpretado de forma coerente por Daniel, "as crianças adquirem verdadeiros conhecimentos somente porque, observando apenas coisas relativas às necessidades mais prementes, não se enganam, ou, se se enganam são logo advertidas de seus equívocos". (p.65)

Mateus (13 anos) relata sua experiência com as atividades de sensação desenvolvidas na escola quando fez a primeira série. "Em uma mesa tinha coisas que exalavam um cheiro forte que com os olhos vendados tínhamos que saber do que se tratava. Era frutas cítricas, vinagre, perfume...”.

Os odores agradáveis causam prazer, nos conta Condillac (1947/1963, p.69), enquanto que ao concentrarmos num odor desagradável experimentamos o sofrimento. Entretanto só podemos desejar um outro sentimento caso tenhamos vivido a experiência que possa relacionar com ele. Tal como a estátua o desembaralhamento das sensações, que nos chegam simultaneamente, se dá pela repetição de várias sensações (agradáveis e desagradáveis) através de um mesmo órgão, em questão o nariz, isto é, cada qual por seu turno.

Mateus (13 anos), assim como Victor, foi estimulado pela escola a aguçar o paladar. Ele relata que em uma outra mesa na sala de aula havia uma que era reservada para sentirem o gosto de coisas salgadas (queijo), doces (balas), azedas (limão) e amargas (chá de boldo).

Recorri a todos os meios para despertar estas últimas disposições utilizando as guloseimas mais cobiçadas pelas crianças... Mas a aversão que manifestou por todas as substâncias açucaradas e pelos pratos mais delicados revelou-se completamente intransponível. Tentei então o uso de pratos fortes, julgando-os apropriados para the exercitar os sentidos forçosamente embotados pelo uso de alimentos grosseiros. Não consegui melhores resultados; foi em vão que lhe ofereci, quando sentia fome ou sede, licores fortes e alimentos condimentados (Itard, p.158).

Já discuti anteriormente, no caso do cheiro da pipoca, a relação que a teoria sensualista estabelece entre memória, capacidade de comparação e de julgamento. Dentro da perspectiva do Tratado das Sensações, diz-se que quanto maiores são as oportunidades da memória exercitar-se, tanto mais fácil será sua atividade mental (1947/1963, p.73).

No livro A Lógica ou Os Primeiros Desenvolvimentos da Arte de Pensar Condillac (1780/1984) discuti como a própria natureza nos ensina sobre a origem, e a geração das idéias e das faculdades da alma. Para ele a criança adquire conhecimento somente quando 
diferencia uma grande quantidade de coisas e é capaz de notar melhor as qualidades que as distingue. Os nossos conhecimentos começam pelo primeiro objeto que aprendemos a diferenciar. Pelo ato analítico.

Aprender a diferenciar as qualidades do doce, do salgado, do azedo e do amargo parece ser o propósito da atividade que Mateus se submetera de olhos fechados. Assim, segundo a teoria sensualista, acredita-se que poderia regular melhor os seus sentidos.

\section{LIÇÃO NÚMERO 5: Ouvindo e produzindo sons}

Oliveira e Wykrota (1990) propõem uma história muda em quatro quadros que ilustra a situação de um pernilongo que incomoda o sono de uma criança dormindo. De orelha em pé, trás um alerta para os problemas dos barulhos e a necessidade de silêncio em alguns momentos, ilustrada por ambientes diferentes (biblioteca, hospital, quarto com menino dormindo, sala de aula), além da exploração de músicas e de instrumentos musicais. Produzindo sons com o corpo é a última atividade mais diretamente relacionada à exploração dos sentidos.

A falta de atenção por parte da alma é interpretada pelos sensualistas como falta de sensibilidade do órgão daí que Itard (1801) declara seu plano de desenvolvê-la a qualquer custo, por todos os meios possíveis (p.151). As explosões com armas de fogo serão tentadas bem junto ao menino selvagem para ver como ele reage. Itard (1801) relata que "o órgão do ouvido mostrava-se insensível aos mais violentos ruídos e à música mais suave; a voz reduzida ao estado de completa mudez, deixando escapar apenas um som gutural e uniforme" (p.138). Entretanto é digno de nota o fato de Victor estar sempre atento, por mais silenciosa que fosse a atitude de alguém abrir uma castanha em suas costas, aos sons que eram produzidos.

Com Mateus fora tentado aos sete anos uma experiência com a produção de sons a partir de diferentes instrumentos. Ele relata que em uma mesa eram colocados objetos que emitiam sons, como buzina, apito e campainha. A cada som emitido próximo do ouvido as crianças tinham de dizer que som era aquele, com que estava associado, se a um brinquedinho de bebê, corneta, apito ou campainha de casa, etc.

$\mathrm{Na}$ lição Olho vivo, Daniel relata que a professora "mandava a gente olhar uma pessoa de longe depois ela de perto para saber como os olhos funcionam. Depois a gente ficava de olhos tampados e depois abria para sentir a diferença".

\section{SOBRE A HISTÓRIA DOS MANUAIS DIDÁTICOS: UMA TENTATIVA QUE RECUPERAR AS ORIGENS DAS ABORDAGENS SENSUALISTAS NO ENSINO DE CIÊNCIAS.}

Diante das inúmeras aproximações entre as incitavas pedagógicas no ensino de ciências nas séries inicias e a teoria do conhecimento condillaciano, fez-se necessário tentar compreender se estamos diante de simples coincidências ou se seria uma prática repetida entre os professores de ciências, guiados pela formação ambientalista e pelos manuais didáticos, que incorporam atividades, às vezes, sem questionar a validade e a importância no desenvolvimento cognitivo do aprendiz. 
Vou me ater na tese de que as filiações epistemológicas e suas conseqüências pedagógicas são pouco explicitadas. Há uma certa inércia naquilo que se toma como objeto de ensino na tradição dos manuais didáticos e que seguem repetindo por séculos à fora. $O$ Manual de Ensino Elementar ${ }^{5}$ de N. A Calkins de 1884, foi traduzido e adaptado por Ruy Barbosa em 1886 e é a referência mais antiga encontrada que apresenta as idéias aqui discutidas. No preâmbulo das "Primeiras Lições de Coisas" o tradutor fala da admissão no programa das escolas dessas lições, em função das reformas de ensino nas várias províncias.

Ruy Barbosa (1886), a exemplo de Condilllac (1947/1963), fala do mau serviço prestado por um ensino baseado na memorização de lições de coisas simplesmente listadas onde perguntas e respostas que não despertam o interesse das crianças são repetidas mecanicamente. Criticando outros manuais didáticos, exemplifica: "As árvores podem ser: compridas, baixas, ramosas, esgalhadas, pontudas, frondosas, vicejantes, amareladas, florescente, secas, direitas, pensas". "As abelhas são espertas, úteis, animosas, laborosas, anegradas, felpudas, aladas" ( $p$. XI). Após vários exemplos dessa natureza, o tradutor lembra um alemão, F. Busse, diretor da Escola Superior de meninas de Berlim, ao estabelecer os fins imediatos do processo pedagógico:

1. O ensino objetivo há de adaptar-se ao caracter especial de meio de educar os sentidos. Essa educação consistirá em exercícios de observação, que desenvolvam a energia latente de cada sentido, com particularidade a da vista. 2. O fim principal do ensino intuitivo será desenvolver os modos de observar as condições de aplicação das leis do pensamento. A estes denominamos exercícios de reflexão. 3. Outro instituto essencial seu é o desenvolvimento da linguagem, consistindo todas as lições dessa ordem em exercícios de falar e escrever. Na base primordial de tudo avulta a cultura dos sentidos, à qual cumpre recorrermos como o principal instrumento de todo o ensino (p. XII).

No prefácio da Primeira, da Décima Quinta e da Quadragésima Edição o recado mais forte é de natureza empirista ao afirmar que "a observação é absolutamente a base de todo o conhecimento", o que justifica a tradução que Ruy Barbosa faz para a expressão object lesson: "instrução pelas próprias coisas e não instrução acerca das coisas" (p. XI).

Os princípios fundamentais das lições das coisas são essencialmente aqueles de base empirista e sensualista já comentados anteriormente, que se desdobram em outras discussões sobre a educação doméstica dos sentidos, da necessidade de cultivar as faculdades de observação e do uso da palavra. Capítulos interessantes são dedicados a educação do ouvido, a distinção de sons, dentre outros. Dois capítulos deverão ocupar atenção devido à forte proximidade com as atividades propostas por Oliveira e Wykrota (1990). O primeiro chama-se "Lições de qualidades" e o segundo "Órgãos dos sentidos".

Uma síntese do capítulo dedicado aos princípios das lições das coisas propostos na tradução do Manual de Ensino elementar de Calkins está apresentada a seguir:

- É pelos sentidos que nos advém o conhecimento do mundo material.

- A percepção é a primeira fase da inteligência.

- A existência de uma noção no espírito nasce da percepção das semelhanças e diferenças entre os objetos.

\footnotetext{
${ }^{5}$ Calkin's New Object Lessons. Primary object lesson for training the senses and developing the faculties of children. A Manual of elementary instruction for parents and teachers. By N. A Calkins. Fortieth edition. Revised. New York, 1884.
} 
- Todas as faculdades prosperam, e robustecem a poder de exercício adequado.

- Algumas das energias mentais são já nas crianças muito ativas: sensação, percepção, observação, comparação, memória simples e imaginação. Enquanto que a razão, memória filosófica e generalização são próprias da idade adulta.

- O melhor, e natural incentivo para obter a atenção e aquisição do conhecimento das crianças é a recreação.

- O bom ensino inspira contentamento à infância.

- Os hábitos de atenção são permanentes fontes de educação intelectual.

- O processo natural de ensinar parte do simples para o complexo; do que se sabe, para o que se ignora; dos fatos, para as causas; das coisas para os nomes; das idéias para as palavras; dos princípios, para as regras.

Sem dúvida é possível afirmar a atualidade de vários desses princípios. Acreditavase, como ainda se acredita hoje, que o professor nada pode ensinar antes de saber o que a criança conhece sobre o assunto, as noções já aprendidas, as que deixaram dúvidas e que é necessário que ele seja capaz de escolher métodos para sanar as dificuldades e fazer os aprendizes progredirem na aquisição do conhecimento.

Calkins sugere que em casa as crianças devem exercitar os sentidos que são as portas e janelas do espírito. Registra que quando a criança não discrimina bem os sons ela é taxada de estúpida Em casa devem adestrar os sentidos de cheirar, gostar e apalpar, lugar mais adequado para isso, no julgamento do autor. Ao contrário, na escola seria consagrado o exercício de ouvir e de ver, merecendo um reforço escolar no desenvolvimento da audição e da visão. No âmbito doméstico seriam incentivadas a mexerem nas coisas, experimentarem diferentes sensações. Enfim, ampliarem os sentidos. Para isso são sugeridos exercícios domésticos de visão rápida; distinção de objetos pelos sons; distinção de pessoas pela voz e pelo pisar; distinção pelo sabor de pães, doces, manteiga, etc.; distinção de substâncias azedas, picantes, adstringentes, amargas,salgadas e doces.

Em seguida vem sugerida uma série de exercícios para educar o olfato. O primeiro deles se assemelha ao que foi descrito por Mateus (13 anos). Com os olhos vendados e sem auxílio do tato, distinguir café, vinagre, maçãs, laranjas, cebolas, etc. Dizerem os nomes, sem ver, de cânfora, hortelã-pimenta, cebola, canela, etc.

Os exercícios para educar o tato também são os já nossos conhecidos. Distinguir objetos, pessoas, moedas, grãos, o áspero do liso, substâncias rígidas das macias, quentes das frias, tamanhos e formas, tipos de folhas, etc. Para cada uma das qualidades das coisas é apresentado um rol de objetos ou de substâncias para exercitarem, seja em casa, seja na escola. Muitos outros exercícios estão descritos de forma detalhada, tal como encontramos nos manuais didáticos atuais.

As lições acerca dos órgãos dos sentidos discutem detalhadamente os olhos, as orelhas, ouvido, nariz, boca, dentes, ossos e pele. O estudo do olho é feito descrevendo a anatomia do rosto e dos órgãos que o compõe: pálpebras, pestanas, sobrancelhas, a função das lágrimas, etc. De forma semelhante prossegue com o estudo de todos os órgãos, dando atenção aos cuidados dispensados aos olhos, pele, nariz, escovação de dentes, etc. 


\section{CONSTRUINDO ALGUMAS SÍNTESES}

A atualidade de Condillac pode ser notada na pedagogia na medida em que critica a educação centrada na atividade de memorização. Ele considera que desde muito cedo as crianças usam a razão e, portanto a escola não pode limitar-se a cultivar a memorização. Não se trata de dar às crianças todo o conhecimento de que vão precisar, mas de ensiná-las a pensar. A pedagogia tradicional calcada na oratória, na recitação de "pontos" pode ser em parte debitada a influência das idéias sensualistas. Não no que se refere à memorização, mas à arte de proferir discursos.

A infância, na concepção sensualista, é o tempo da aprendizagem dos sentidos. Quanto mais adulto mais difícil se torna o desenvolvimento das sensações. Portanto, dessa perspectiva compreendemos a razão de se iniciar o estudo de ciências pela exploração dos órgãos dos sentidos.

Foi na confluência do racionalismo cartesiano e iluminista que surgiu uma orientação empírico-sensualista que é, por vezes, praticada nas aulas de ciências naturais em diferentes níveis de ensino. Perspectiva difícil de se argumentar favoravelmente a ela na atualidade. O pensamento analítico, segundo os sensualistas advém do desembaralhamento das idéias que chegam simultaneamente pelos nossos órgãos dos sentidos. O desenvolvimento de cada sensação separadamente constrói a percepção que é definida como a primeira operação do entendimento do mundo.

Da percepção origina-se a consciência de saber o que se passa à volta. A atenção seria a base de toda forma de discernimento, já que implica na capacidade do centramento em algumas percepções. Consciência e atenção, por sua vez, permitiriam as reminiscências, isto é, a memória de já haver sentido algo no passado. Um efeito da atenção sobre a consciência seria a imaginação.

Sintetizando, podemos dizer que:

Haveria ao longo do desenvolvimento do indivíduo um progresso desdobrado entre as operações. O funcionamento ou o exercício daquelas mais simples levaria ao aparecimento de novas e ao controle destas por outras de maior complexidade. Assim é que a reflexão, operação complexa colocaria o homem senhor de sua atenção, permitindo-lhe ligar idéias, o que, por sua vez, subsidiaria a memória. Daí adviria a análise de onde se formaria a reminiscência. $O$ trabalho integrado da reflexão com a memória tornaria possível a concepção, ou a possibilidade do homem em formar conceitos (Souza 1997, p. 167).

A formação de conceitos é um dos objetivos perseguidos pelo ensino de ciências. Se se concebe a formação dos conceitos pela via acima descrita faz sentido investir nas atividades ligadas à sensação. Caso contrário essa perspectiva precisa ser ultrapassada por outro mais coerente com o que sabemos sobre a formação de conceitos.

De igual modo podemos perguntar pela contribuição da corrente sensualista na aquisição da linguagem. Para os sensualistas o discurso sendo linear e seqüencial ajuda a organizar o mundo e, portanto, a linguagem permite a análise do pensamento. Concepção orientadora da expressão: "fala que as coisas ficam mais claras". A princípio as crianças seriam confusas em decorrência das sensações que lhes chegam amalgamadas do exterior. Daí, a necessidade de se instrumentalizar o espírito pela via da linguagem oral e escrita. $\mathrm{Na}$ fase de alfabetização das crianças não poderia haver nada mais sugestivo do que atividades 
para "clarear a alma". Podemos perguntar sobre que relação existe para Condillac entre a linguagem oral e linguagem escrita, propósito central nos primeiros anos escolares.

Para Condillac, desde muito antes das crianças aprenderem a falar, elas pensam. Portanto, o pensamento seria anterior à palavra, mas trata-se de pensamento confuso, a linguagem é que o clareia. Da mesma forma, antes das crianças aprenderem a escrever elas já falam. Assim uma fala clara resultaria num pensamento esclarecido ou organizado e numa escrita que não só comunica o pensamento, mas que também está imbricada na própria organização do pensamento.

Contudo, podemos partir de outros referenciais e dizer que as capacidades humanas são produções culturais engendradas a partir das relações que estabelecemos com o mundo e com os outros. Se tomarmos Benviniste (1991) como referência podemos falar da natureza meramente instrumental da linguagem que é conferida por Condillac. É na e pela linguagem que o homem se constitui. É o homem falando que encontramos no mundo. Quero dizer com isso que podemos nos servir de outra teoria da linguagem que explique de modo diferente a relação entre pensamento e linguagem, bem como a formação dos conceitos. Desse outro horizonte cabe seguir indagando sobre a validade de se ensinar ciências partir dos órgãos dos sentidos. Essa discussão merece uma outra pesquisa sobre o que efetivamente as crianças em idade de alfabetização aprendem com as experimentações de cunho sensualista? Qual a importância e o papel do estudo das sensações para crianças, jovens e adultos que vivem num mundo saturado de cores, sons, cheiros, etc.? Outra questão também pertinente de ser investigada refere-se ao que as crianças de fato conhecem da sua relação com o mundo quando ainda bebês. Sabem distinguir entre o áspero e o macio?, o doce e o amargo?, o frio e o quente?, o claro e o escuro?, o cheiro da mãe e dos estranhos? Como é, e quando é, que uma criança distingue sons? Em outras palavras, reconhece, por exemplo, a voz da mãe, o latido do cachorro ou o toque da campainha? Contudo, responder a essas indagações está para além do que se pretendeu aqui. 


\section{REFERÊNCIAS BIBLIOGRÁFICAS}

BENVENIST, E. Da Subjetividade na linguagem. In: Problemas de lingüística geral I. Campinas: Editora Unicamp, 1991.

CALKINS, N. A .Primeiras Lições de coisas. Trad. Ruy Barbosa. Rio de Janeiro: Imprensa Nacional, 1886.

CHAUÍ, Marilena. Janela da alma, espelho do mundo. In: NOVAES, A (org). O Olhar. São Paulo: Cia. Das Letras, 1993, 4를 reimpressão, p. 31-63.

MONDOLFO, Rodolfo. Estudo preliminar do Tratado de las Sensaciones de, Étienne Bonnot Condillac. Trad. Weinberg, G. Texto original 1947. Buenos Aires: Editora Universitária de Buenos Aires, 1963.

ITARD, Jean M G. Memória e Relatório de Victor de Aveyron, 1801. (texto xerografado e disponibilizado pela professora Luci Banks-Leite).

Os pensadores. Condillac, Helvéticus e Degerando. Textos escolhidos. São Paulo: Abril Cultural, 1984/1754.

Os Pensadores. John Locke - Ensaio Acerca do Entendimento Humano. Trad. AIEX, Anoar. São Paulo: Nova Cultural, 1997.

OLIVEIRA, N. R. \& WYKROTA, J. L. M. Ciências - Descobrindo o Ambiente. Vol. 1 Belo Horizonte: Formato, 1990.

SOUZA, REGINA M. .Que palavra que te falta. Tese de doutorado. UNICAMP: 1997.

Data de recebimento: 20/10/2003

Data de aprovação: 29/01/2004 